\title{
PRINCIPAL COMPONENT ANALYSIS TO EVALUATE THE SPATIAL VARIATION OF MAJOR ELEMENTS IN KAOLIN DEPOSIT
}

\author{
Georges-Ivo E. Ekosse ${ }^{1^{*}}$ and Kassim S. Mwitondi ${ }^{2}$ \\ ${ }^{1}$ Directorate of Research and Innovation, University of Venda, Thohoyandou, Limpopo \\ Province, 0950 South Africa \\ ${ }^{2}$ Computing and Communication Research Group, Faculty of Arts, Computing, Engineering and \\ Sciences, Sheffield Hallam University, Sheffield S1 1WB, UK
}

(Received December 22, 2013; revised September 8, 2014)

\begin{abstract}
This paper explores the variations in major elements concentrations in kaolins from four different deposits in Botswana. The data were obtained from four different kaolin deposits with an additional four-class label based on particle sizes of the rock - providing a natural comparative basis between detected structural features with those of the original data attributes. Using principal component analysis (PCA), the paper reduces the data dimensionality and establishes inherent distinctive attributes of major elements accounting for the highest variation in chemical compositions of the kaolins. The principal components extracted are validated using graphical data visualization tools applied on a $28 \times 11$ - dimensional data matrix of the oxides of $\mathrm{Na}, \mathrm{Mg}, \mathrm{Al}, \mathrm{Si}, \mathrm{P}$, $\mathrm{K}, \mathrm{Ti}, \mathrm{Mn}$ and $\mathrm{Fe}$, and loss on ignition (LOI). The validated results show that structures based on three retained components exhibit clearly discernible variations within the samples. Discretisation of the particle sizes is highlighted as both a challenge and an opportunity and it is recommended that it be used as a tuning parameter in gauging kaolin variations across samples and in validating new predictive modeling applications. Successful applications will depend on how clay and data scientists keep track, synchronise and share information relating to potentially dynamic data such as the impact of discretisation of kaolin particle sizes.
\end{abstract}

KEY WORDS: Graphical data visualization, Kaolin, Kaolinite, Particle size, X-Ray fluorescence spectrophotometry, Multi-collinearity

\section{INTRODUCTION}

Kaolin is a rock term in which kaolinite is the most abundant and commercially most valuable mineral; with others being halloysite, nacrite and dickite. It could be primary or secondary depending on its genesis and sediment provenance. The most common parent minerals from which it develops are feldspars and muscovite which are present in granitic and rhyolitic rocks as well as in feldspathic arenites and sandstones. The transformation of muscovite and $\mathrm{K}$ feldspar into kaolinite is summarised in equations 1 and 2 [1-3].

$$
\begin{array}{lc}
2 \mathrm{KAl}_{3} \mathrm{Si}_{8} \mathrm{O}_{10}(\mathrm{OH})_{2}+2 \mathrm{H}^{+}+3 \mathrm{H}_{2} \mathrm{O} \rightarrow 3 \mathrm{Al}_{2} \mathrm{Si}_{2} \mathrm{O}_{8}(\mathrm{OH})_{4}+2 \mathrm{~K}^{+} \\
\text {Muscovite } & \text { Kaolinite } \\
2 \mathrm{KAlSI}_{3} \mathrm{O}_{8}+2 \mathrm{H}^{+}+9 \mathrm{H}_{2} \mathrm{O} \rightarrow \mathrm{Al}_{2} \mathrm{SI}_{2} \mathrm{O}_{8}(\mathrm{OH})_{4}+2 \mathrm{~K}^{+}+4 \mathrm{H}_{4} \mathrm{SI} \\
\text { K-feldspar } & \text { Kaolinite }
\end{array}
$$

These reactions occur simultaneously with others depending on the parent materials, and geochemical environment of formation. In this vein, it is common to find kaolin associated with other mineral assemblages that are accountable for its surface and structural impurities. It is therefore crucial to understand what chemical impurities are contained in kaolin and how they influence one another. This has risen the need for research being directed at characterising kaolins using a variety of data analytical techniques. Some of the methods used in characterising clays and particularly kaolins, are reported [4-7].

\footnotetext{
*Corresponding author. E-mail: ekosseg@gmail.com
} 
One of the most appropriate statistical technique used in analysing heterogeneity and complexity inherent in clay minerals based on the relationship between their physical and chemical properties on the one hand and their individual elemental components on the other [8], is principal component analysis (PCA). Recent applications of PCA include comparison of irrigation sources based on soils [9], soil contamination due to industrial activities [10], kaolin fractal dimension [11], modification of kaolinite surfaces [12], composition of lacustrine sediments [13], and porcelain bodies in relation to raw materials [14].

Principal component analysis could be applied to data dimensional reduction by identifying and extracting the main components which account for the highest variation in the whole dataset. Typically, the reduction amounts to addressing multi-collinearity, and its presence could lead to the emergence of different, but equally well fitting regression models. It could render the identification of an optimal model unreliable which may seriously hamper understanding of clay minerals chemical compositions. Though these characterisation techniques have yielded an increase in the understanding of clay minerals, the studies have raised concerns about sample limitations and multi-collinearity of the clay minerals' attributes.

Application of the PCA in characterising major elements concentrations in African kaolins has not been documented. This paper thus investigates the key characteristics of samples of kaolins from different deposits by first reducing the dimensionality of the oxides using PCA. The objectives of the paper are two-fold: to use PCA in identifying the main elemental oxides accounting for the highest variation in the studied kaolin samples; and to validate the PCA results using graphical data visualization tools. On the basis of the objectives, the paper seeks to address how naturally arising structures in major elements concentrations of kaolins could be optimally utilized in understanding variations in major elements compositions of kaolins from Botswana.

\section{EXPERIMENTAL}

\section{Kaolin sources and samples}

Kaolin samples for the study were taken from Serule $\left(21^{\circ} 59^{\prime} 06^{\prime \prime} \mathrm{S} ; 27^{\circ} 20^{\prime} 16^{\prime \prime} \mathrm{E}\right)$, Makoro $\left(22^{\circ} 39^{\prime} 50^{\prime \prime} \mathrm{S} ; 27^{\circ} 05^{\prime} 05^{\prime \prime} \mathrm{E}\right)$, Kgwakgwe $\left(25^{\circ} 00^{\prime} 05^{\prime \prime} \mathrm{S} ; 25^{\circ} 19^{\prime} 30^{\prime \prime} \mathrm{E}\right)$ and Lobatse $\left(25^{\circ} 41^{\prime} 02^{\prime \prime} \mathrm{S}\right.$; $25^{\circ} 12$ '04'E) kaolin deposits in Botswana. A random sampling method was used to sample soils to a depth of $20 \mathrm{~cm}$ or more within several survey units within each region. To minimize sampling error, all the units of the survey area were included to cover the inherent variations among soil units. A soil auger and a geological hammer were used for the collection of samples.

Serule kaolin consists of kaolinitic clays associated with the Karoo Mudstones; formed from the reaction of felsdpathic arenites with meteroric waters under intense weathering conditions, accompanied by the leaching of $\mathrm{K}$ and/or Na contained in the feldspars [15]. The Makoro kaolin was derived from arkose, which may possibly have originated from regional surrounding feldspar-rich granitic rocks [2]. Kgwakgwe kaolin was formed from the weathering profiles of the source rocks, transported and deposited in managaniferous shales, which was further refined by acidic leaching due to the alteration of $\mathrm{MnCO}_{3}$ to $\mathrm{Mn}$-oxides occurring locally in the basin. Kaolinisation was controlled by fluid acidity rather than fluid temperature [3]. Lobatse kaolin is comprised of kaolinitic clays which were formed from deeply weathered shales [16, 17]. Mineralogical constituents and physico-chemical properties of the clay fraction in the four kaolins are summarised in Table 1.

Kaolinite is present in the clays. Serule kaolin was monomineralic. Smectite and quartz occur in both Lobatse and Makoro kaolins. At least $71.2 \mathrm{wt} \%$ of the kaolins consisted of particles which were $<2 \mu \mathrm{m}$. The particle density (PD) (also known as the relative density) of the kaolins compare well with that of pure kaolinite (2.67) [18]. As shown in Table 1, the colour, feel, and hardness are all consistent with kaolins. 
Principal component analysis to evaluate spatial variation of major elements in kaolin deposit 43

Table 1. Minerals contents and physico-chemical properties of studied kaolins [15].

\begin{tabular}{|c|c|c|c|c|}
\hline $\begin{array}{l}\text { Minerals contents and physico- } \\
\text { chemical properties }\end{array}$ & Kgwakgwe & Lobatse & Makoro & Serule \\
\hline \multicolumn{5}{|l|}{ Mineral composition } \\
\hline - $\quad$ Kaolinite & $\mathrm{x}$ & $\mathrm{x}$ & $\mathrm{x}$ & $\mathrm{x}$ \\
\hline - Muscovite & $\mathrm{x}$ & $\mathrm{x}$ & $\mathrm{x}$ & - \\
\hline - Smectite & - & $\mathrm{x}$ & $\mathrm{x}$ & - \\
\hline - Quartz & - & $\mathrm{x}$ & $\mathrm{x}$ & - \\
\hline \multicolumn{5}{|l|}{ Average weight percent grain size } \\
\hline - $\quad \mathrm{Wt} \%<20 \mu \mathrm{m}$ & 90.50 & 90.10 & 91.50 & 94.05 \\
\hline - $\quad \mathrm{Wt} \%<2 \mu \mathrm{m}$ & 80.10 & 71.20 & 76.75 & 89.10 \\
\hline Particle density & 2.67 & 2.68 & 2.68 & 2.65 \\
\hline Hue/value/chroma & $7.5 \mathrm{YR} / 8 / 1$ & $7.5 \mathrm{YR} / 8 / 2$ & $7.5 \mathrm{YR} / 8 / 2$ & $7.5 \mathrm{YR} / 8 / 1$ \\
\hline Color & White & Pink white & Pink white & White \\
\hline Feel & $\begin{array}{l}\text { Very soft and } \\
\text { slightly soapy }\end{array}$ & $\begin{array}{l}\text { Soft, soapy and } \\
\text { slightly gritty }\end{array}$ & $\begin{array}{c}\text { Soft, and } \\
\text { soapy }\end{array}$ & $\begin{array}{l}\text { Very soft and } \\
\text { very soapy }\end{array}$ \\
\hline Hardness (Mohr) & 2.25 & 3.00 & 2.50 & 2.00 \\
\hline
\end{tabular}

\section{Major elements analysis}

Two representative samples were collected from each of the four kaolin deposits. The representative samples were labeled based on their source deposits as follows: Serule $=$ DS, Makoro $=$ DM, Kgwakgwe $=$ DK, and Lobatse $=$ DL. The samples were fractionated into three classes: clay $(<2 \mu \mathrm{m})$, silt $(>2 \mu \mathrm{m}, \mathrm{S} \leq 20 \mu \mathrm{m})$, and sand $(\geq 20 \mu \mathrm{m}, \mathrm{S} \leq 53 \mu \mathrm{m})$. For samples identification, each of the three particle size classes were denoted A, B, and C, respectively; and the whole rock of kaolin was labeled W. A total of 28 percentage readings for 11 concentrations of oxide elements forming a $28 \times 11$ data matrix were obtained from the four different kaolins (Table 2).

Table 2. Representative samples labeled according to their source deposits (values are in $\% \mathrm{w} / \mathrm{w}$ ).

\begin{tabular}{|c|c|c|c|c|c|c|c|c|c|c|c|c|}
\hline $\begin{array}{c}\text { Particle } \\
\text { size }\end{array}$ & Kaolin & $\mathrm{Na}_{2} \mathrm{O}$ & $\mathrm{MgO}$ & $\mathrm{Al}_{2} \mathrm{O}_{3}$ & $\mathrm{SiO}_{2}$ & $\mathrm{P}_{2} \mathrm{O}_{5}$ & $\mathrm{~K}_{2} \mathrm{O}$ & $\mathrm{CaO}$ & $\mathrm{TiO}_{2}$ & $\mathrm{MnO}$ & $\mathrm{Fe}_{2} \mathrm{O}_{3}$ & LOI \\
\hline $1 \mathrm{~A}$ & DS & 0.1 & 0.15 & 34.1 & 44.7 & 0.118 & 0.72 & 0.01 & 1.38 & 0.026 & 1.85 & 14.9 \\
\hline 1B & DS & 0.15 & 0.11 & 31.2 & 49 & 0.101 & 1.02 & 0.03 & 1.36 & 0.031 & 1.67 & 13.5 \\
\hline $1 \mathrm{C}$ & DS & 0.2 & 0.09 & 28.9 & 53.1 & 0.093 & 1.2 & 0.02 & 1.48 & 0.052 & 1.62 & 11.6 \\
\hline $2 \mathrm{~A}$ & DS & 0.06 & 0.14 & 34.2 & 44.9 & 0.117 & 0.72 & 0.01 & 1.38 & 0.025 & 1.85 & 14.8 \\
\hline $2 \mathrm{~B}$ & DS & 0.14 & 0.12 & 31.5 & 49.5 & 0.106 & 1.04 & 0.02 & 1.36 & 0.031 & 1.69 & 13.5 \\
\hline $2 \mathrm{C}$ & DS & 0.2 & 0.08 & 28.4 & 53.8 & 0.09 & 1.23 & 0.03 & 1.51 & 0.055 & 1.6 & 11.5 \\
\hline W & DS & 0.13 & 0.09 & 28.7 & 51.8 & 0.1 & 0.94 & 0 & 1.27 & 0.032 & 1.58 & 13.3 \\
\hline $1 \mathrm{~A}$ & DM & 0.07 & 0 & 27.6 & 55.9 & 0.052 & 0.23 & 0 & 1.36 & 0.024 & 2.64 & 10.5 \\
\hline $1 \mathrm{~A}$ & DK & 0.07 & 1.1 & 30.9 & 49.1 & 0.07 & 4.21 & 0 & 0.737 & 1.23 & 1.29 & 9.4 \\
\hline 1B & DL & 1.04 & 1.53 & 18.2 & 62.7 & 0.084 & 3.18 & 0.24 & 0.869 & 0.066 & 6.39 & 5.2 \\
\hline $\mathrm{W}$ & DL & 1.09 & 1.6 & 15.8 & 64.2 & 0.08 & 2.83 & 0.24 & 0.72 & 0.106 & 7.53 & 4.6 \\
\hline \multicolumn{6}{|c|}{ Particle size } & \multicolumn{7}{|c|}{ Description } \\
\hline \multicolumn{6}{|c|}{ A } & \multicolumn{7}{|c|}{$\mathrm{S}<\mu \mathrm{m}$ (Clay size) } \\
\hline \multicolumn{6}{|c|}{ B } & \multicolumn{7}{|c|}{$2<\mathrm{S} \leq 20$ (Silt size $)$} \\
\hline \multirow{2}{*}{\multicolumn{6}{|c|}{$\frac{\mathrm{C}}{\mathrm{W}}$}} & \multicolumn{7}{|c|}{$20<\mathrm{S} \leq 53$ (Sand size) } \\
\hline & & & & & & \multicolumn{7}{|c|}{ (Whole rock) } \\
\hline
\end{tabular}

The chemical compositions of the kaolin samples were determined using X-ray fluorescence (XRF) spectrophotometry for their major elements compositions. The following oxides: $\mathrm{Na}_{2} \mathrm{O}$, 
$\mathrm{MgO}, \mathrm{Al}_{2} \mathrm{O}_{3}, \mathrm{SiO}_{2}, \mathrm{P}_{2} \mathrm{O}_{5}, \mathrm{~K}_{2} \mathrm{O}, \mathrm{CaO}, \mathrm{TiO}_{2}, \mathrm{MnO}$, and $\mathrm{Fe}_{2} \mathrm{O}_{3}(\mathrm{t})$, and loss on ignition (LOI) were analysed for the different fractions of the samples as well as for the whole rock as described by Fitton [19]. The analyses of the oxides of the major elements were conducted on glass disks. Milled samples were roasted at $1000{ }^{\circ} \mathrm{C}$ for 3 hours to oxidise $\mathrm{Fe}^{2+}$ and $\mathrm{S}$ and to determine the loss of ignition (LOI). One gram of roasted sample and $9 \mathrm{~g}$ of flux consisting of $34 \% \mathrm{LiBO}_{2}$ and $66 \% \mathrm{Li}_{2} \mathrm{~B}_{4} \mathrm{O}_{7}$ were fused at $1050{ }^{\circ} \mathrm{C}$ to form stable glass disks.

\section{Application of PCA}

Focusing on the 10 elemental oxides and the LOI obtained from chemical analysis of the kaolins, PCA was applied to condense the 11 numerical attributes into a set of few attributes accounting for the highest variation in the data. The following finite steps were taken: obtaining kaolin data from data sources; extracting the components accounting for the highest variation; and interpreting the results in conjunction with other data segmentation methods. This application provides an insight into the major elements characteristics of each particular sample and fractionated sample. Dimensional reduction via PCA is considered as a way of unsupervised modeling of data. Each extracted principal component is a linear combination of the total number of variables and the components are extracted sequentially in a descending order of the amount of variation. Thus, from the 11 numerical variables obtained, a maximum of 11 components are extracted which, in mathematical terms, amounts to solving 11 equations with 11 unknowns. In this case, the variance in the correlation matrix is "repackaged" into 11 eigen values with each eigen value representing the amount of variance that is captured by one component. Geometrically they may be viewed as dimensions in 11-space, with each dimension perpendicular to each of the other dimensions. Thus, the extracted factors could be inferred from the correlations among the 11 variables with each component being estimated as a weighted sum of the variables. Thus, the $K^{\text {th }}$ principal component from the obtained data is computed as expressed in Equation 3.

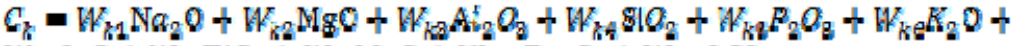 $W_{k \gamma} \mathrm{CaO}+W_{k \beta} \mathrm{T} Q_{2}+W_{k p} \mathrm{MnO}+W_{k 10} \mathrm{Fa}_{2} O_{8}+W_{k 11} \mathrm{LOI}$}

More generally, if there exists a vector $X_{l} \neq \mathbf{v}, \mathbf{1}, \mathbf{2}, p_{l}$ then its $K$ principal components to be extracted are the $K$ random variables $\{j \mid=1,2, \ldots K$ such that:

$$
\begin{aligned}
& C_{1}=W_{1}^{\prime} X_{i}=W_{11} X_{1}+W_{12} X_{2}+\ldots+W_{1 p} X_{p} \\
& C_{2}=W_{2}^{\prime} X_{i}=W_{21} X_{1}+W_{22} X_{2}+\ldots+W_{2 p} X_{p}
\end{aligned}
$$$$
C_{K}=W_{K}^{\prime} X_{i}=W_{K 1} X_{1}+W_{K 2} X_{2}+\ldots+W_{K p} X_{p} \text {. }
$$

The principal components are extracted from the linear combinations of the original variables maximising the variance and having zero covariance with the previously extracted components. The vectors $W_{i j}$ are chosen subject to the following constraints: each of the determinants of weight vectors equals 1 , i.e. $\left\|W_{E}^{*}\right\|=\mathbb{1}_{i}$; each of the principal components, $C_{j}$ maximises $\operatorname{Var}\left(W_{f}^{t} X_{i}\right)$ and $\operatorname{Cov}\left(W_{f}^{t} X_{t}, W_{r}^{t} X_{i}\right)=0 \forall k<r$. Each of the components $C_{k}$ contains each of the variables $X_{i}$ with a corresponding weight. Implicitly, condensation is done on particle sizes and the ultimate goal is to identify the nature of the resulting components based on the information in the row and column attributes. 
An easy way of understanding PCA and variance maximisation is to envision the rotation of the dependent variable in a 2-D space so that it approximates the regression line. For instance, if we were to investigate the bivariate relationship between an independent variable, say, $\mathrm{Al}_{2} \mathrm{O}_{3}$ and a dependent variable $\mathrm{K}_{2} \mathrm{O}$, the rotation would imply maximising the variability of $\mathrm{K}_{2} \mathrm{O}$ while minimising that of the regression line. Two of the most commonly used guidelines in extracting principal components are the eigen value [20] and the Scree plot [21] methods. The former retains only those components with eigen values larger than 1 - that is, only those components extracting at least as much as the equivalent of one original variable. The latter is also related to eigen values and, typically, the extraction of the components is stopped at the point where the decreasing eigen value plot starts leveling off.

\section{RESULTS AND DISCUSSION}

\section{Major elements analyses}

The results from the XRF analysis show that concentrations for oxides of $\mathrm{Al}$ and $\mathrm{Si}$ are consistent with that of kaolins from other parts of the world [18]; and cater for smectite, muscovite and quartz as well. Other elemental oxides concentrations are due to impurities contained in the kaolin. Figure 1 is the graphical presentations of the log transform of percentages of oxides concentrations of the different size fractions for each of the four kaolins. It is imperative to consider these as discernible natural structures in the data. There are homogeneous features between samples from Serule (DS) and Makoro (DM) with respect to the oxides from $\mathrm{AI}_{2} \mathrm{O}_{3}$ to $\mathrm{K}_{2} \mathrm{O}$ and the heterogeneous features with respect to $\mathrm{CaO}$. Kgwakgwe (DK) samples appear to be most heterogenous. More specifically, $\mathrm{Na}_{2} \mathrm{O}, \mathrm{CaO}$, and $\mathrm{MnO}$ in the different size fractions influence the chemical composition of Serule kaolin. For Makoro kaolin, it is only $\mathrm{MgO}$ in the different size fractions that had an influence in its whole rock chemical composition. All the oxides analysed in the Kgwakgwe kaolin influenced its kaolin chemical composition. Very slight influence of $\mathrm{Na}_{2} \mathrm{O}$, and $\mathrm{MnO}$ in the size fractions could have affected the chemical composition of the Lobatse kaolin.

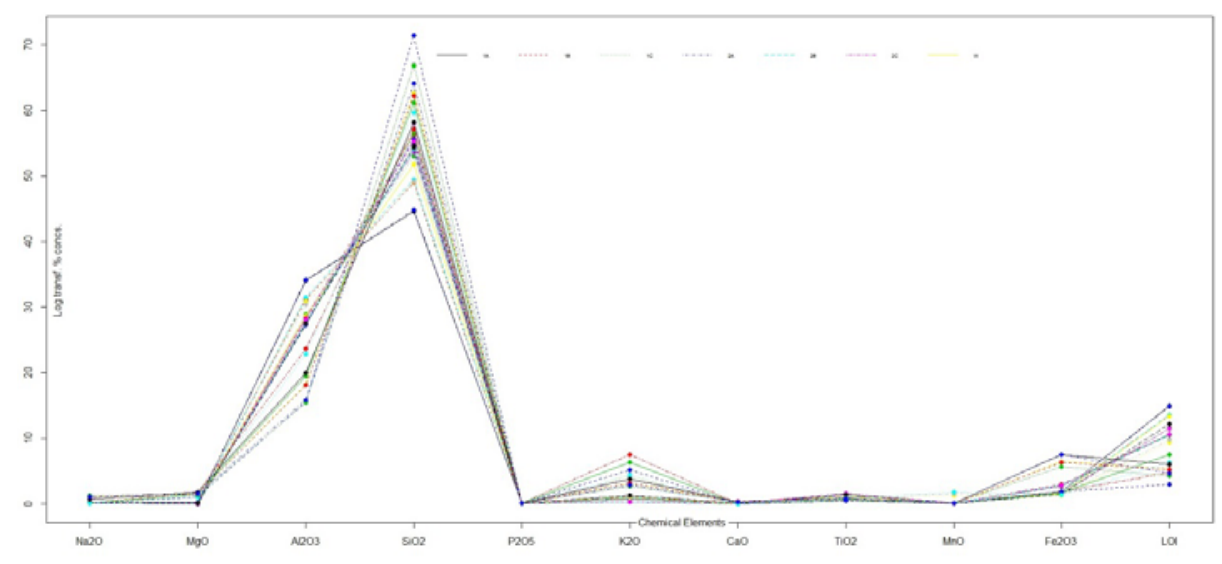

Figure 1. Percentage log transform of oxide concentrations of different sizes for each of the kaolins.

The correlation matrix for the elemental oxides in Table 3 shows strong positive correlations between $\mathrm{Al}_{2} \mathrm{O}_{3}$ and $\mathrm{LOI} ; \mathrm{Fe}_{2} \mathrm{O}_{3}$ and $\mathrm{CaO} ; \mathrm{Na}_{2} \mathrm{O}$ and $\mathrm{CaO}$ as well as strong negative correlations 
between $\mathrm{TiO}_{2}$ and $\mathrm{K}_{2} \mathrm{O} ; \mathrm{SiO}_{2}$ and $\mathrm{Al}_{2} \mathrm{O}_{3} ; \mathrm{SiO}_{2}$ and LOI. There is also evidence of weak correlations between $\mathrm{MnO}$ and $\mathrm{P}_{2} \mathrm{O}_{5}$ on the one hand and other oxides on the other. Overall, the correlation parameters provide some meaningful insights into the relationships among the oxides. The nature of these relationships calls for a dimensional reduction through PCA and as such the decision regarding the number of components to be extracted is crucial. Since the sequential extraction of components implies diminishing variability in the data, this crucial decision is conditioned on the remaining, hopefully random, variability. The right hand side panel in Figure 2 and Table 4 shows that the first three components account for about $91 \%$ of the variability in the data - hence, based on the standard threshold of eigen values, three components were retained. At the same time, based on the Scree plot on Figure 2, five or six main components could probably be retained as the plots levels off beyond 6 .

Table 3. Correlations of the concentrations of the elemental oxides.

\begin{tabular}{|c|c|c|c|c|c|c|c|c|c|c|c|}
\hline & $\mathrm{Na}_{2} \mathrm{O}$ & $\mathrm{MgO}$ & $\mathrm{Al}_{2} \mathrm{O}_{3}$ & $\mathrm{SiO}_{2}$ & $\mathrm{P}_{2} \mathrm{O}_{5}$ & $\mathrm{~K}_{2} \mathrm{O}$ & $\mathrm{CaO}$ & $\mathrm{TiO}_{2}$ & $\mathrm{MnO}$ & $\mathrm{Fe}_{2} \mathrm{O}_{3}$ & $\mathrm{LOI}$ \\
\hline $\mathrm{Na}_{2} \mathrm{O}$ & 1 & & & & & & & & & & \\
\hline $\mathrm{MgO}$ & 0.65 & 1 & & & & & & & & & \\
\hline $\mathrm{Al}_{2} \mathrm{O}_{3}$ & -0.76 & -0.76 & 1 & & & & & & & & \\
\hline $\mathrm{SiO}_{2}$ & 0.62 & 0.58 & -0.95 & 1 & & & & & & & \\
\hline $\mathrm{P}_{2} \mathrm{O}_{5}$ & 0.29 & -0.05 & 0.22 & -0.38 & 1 & & & & & & \\
\hline $\mathrm{K}_{2} \mathrm{O}$ & 0.22 & 0.84 & -0.54 & 0.42 & -0.26 & 1 & & & & & \\
\hline $\mathrm{CaO}$ & 0.92 & 0.68 & -0.71 & 0.53 & 0.33 & 0.23 & 1 & & & & \\
\hline $\mathrm{TiO}_{2}$ & -0.39 & -0.89 & 0.7 & -0.6 & 0.3 & -0.93 & -0.36 & 1 & & & \\
\hline $\mathrm{MnO}-0.16$ & 0.21 & 0.1 & -0.12 & -0.07 & 0.36 & -0.18 & -0.36 & 1 & & \\
\hline $\mathrm{Fe} \mathrm{O}_{3}$ & 0.84 & 0.62 & -0.7 & 0.54 & 0.15 & 0.14 & 0.93 & -0.31 & -0.26 & 1 & \\
\hline $\mathrm{LOI}$ & -0.65 & -0.85 & 0.93 & -0.89 & 0.37 & -0.69 & -0.62 & 0.83 & -0.11 & -0.61 & 1 \\
\hline
\end{tabular}

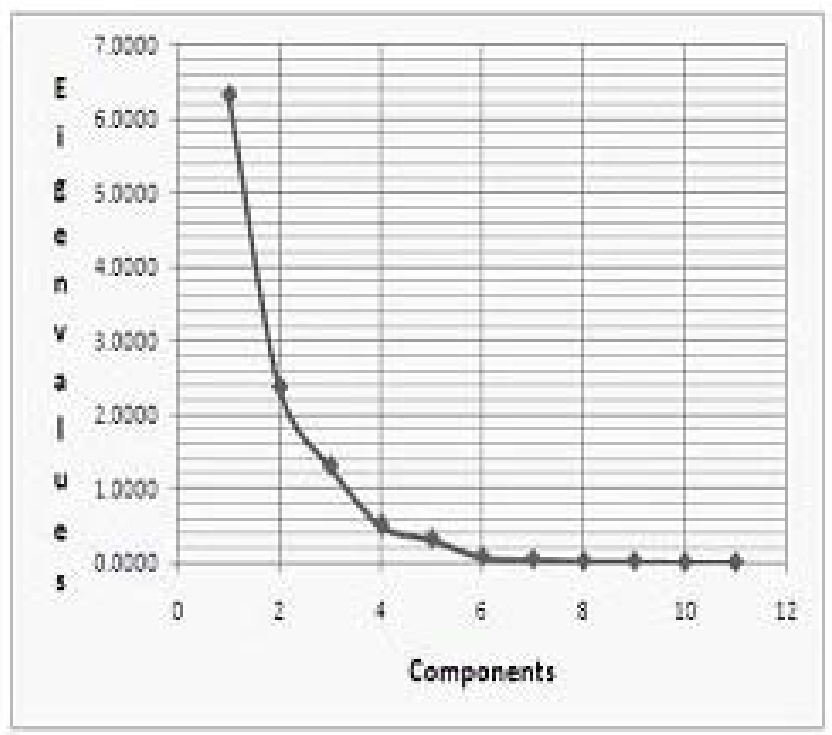

Figure 2. Graphical and numerical illustration of the Eigenvalues and principal components. 
Principal component analysis to evaluate spatial variation of major elements in kaolin deposit 47

Table 4. Numerical illustration of the Eigenvalues and principal components.

\begin{tabular}{|c|c|c|c|c|}
\hline Components & Eigen values & Difference & Proportion & Cumulative \\
\hline 1 & 6.3303 & 3.9546 & 0.5755 & 0.5755 \\
\hline 2 & 2.3757 & 1.0744 & 0.2160 & 0.7915 \\
\hline 3 & 1.3013 & 0.7903 & 0.1183 & 0.9098 \\
\hline 4 & 0.5110 & 0.1887 & 0.0465 & 0.9562 \\
\hline 5 & 0.3222 & 0.2436 & 0.0293 & 0.9855 \\
\hline 6 & 0.0786 & 0.0375 & 0.0071 & 0.9926 \\
\hline 7 & 0.0411 & 0.0218 & 0.0037 & 0.9964 \\
\hline 8 & 0.0193 & 0.0022 & 0.0018 & 0.9981 \\
\hline 9 & 0.0171 & 0.0144 & 0.0016 & 0.9997 \\
\hline 10 & 0.0027 & 0.0021 & 0.0002 & 0.9999 \\
\hline 11 & 0.0006 & \multicolumn{3}{|l}{} \\
\hline
\end{tabular}

\section{Application of PCA}

A concise summary of the results from PCA is graphically presented in Figure 3 in which all the oxides and the loadings associated with each of the extracted components are shown. The radar plot shows that the first component to be extracted had high positive loadings of $\mathrm{CaO}, \mathrm{SiO}_{2}$ and $\mathrm{Fe}_{2} \mathrm{O}_{3}$ with low negative loadings for LOI and $\mathrm{AI}_{2} \mathrm{O}_{3}$. The second component had high positive loadings for $\mathrm{Fe}_{2} \mathrm{O}_{3}, \mathrm{TiO}_{2}$ and $\mathrm{CaO}$ with low negative loadings for $\mathrm{MnO}$ and $\mathrm{K}_{2} \mathrm{O}$. Finally, with the exception of $\mathrm{SiO}_{2}$, all the loadings of the third component lied above zero. The structural relationships between the three retained components - PRIN1, PRIN2 and PRIN3 - were examined by looking at their rotations (Figures $4 \mathrm{a}$ and $4 \mathrm{~b}$ ). Rotations are known to provide excellent ways of visually assessing phenomenal behaviour [22]. Their main purpose is to give a clear pattern of attribute loadings - that is, to highlight the components clearly marked by high or low attribute loadings. In this case, the two rotations visually exhibited "valleys" and "hills" in the data with the three retained components displaying the structure in the kaolin data that would not be apparent in a two-dimensional plot. To obtain a clear visualization of the structural differences between the three components, a SAS built-in 3-D rotation algorithm was used.

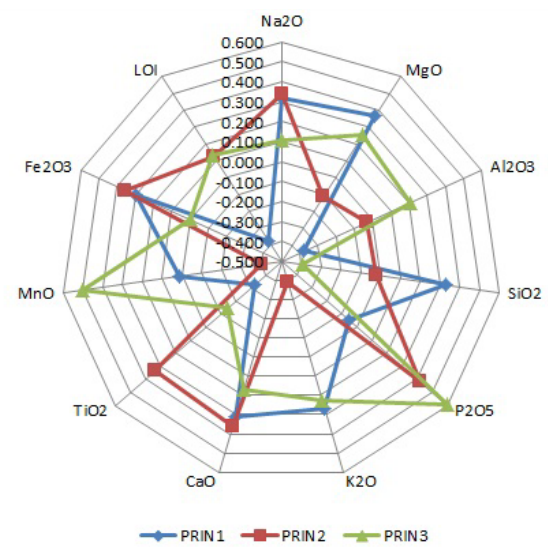

Figure 3. A summary of PCA results showing the retained three main components. 


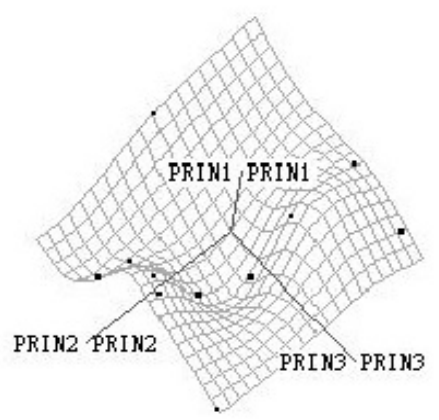

Figure 4a. Rotated 3-D plots for the extracted components.

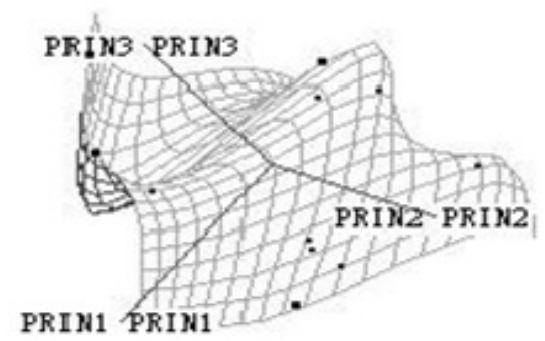

Figure 4b. Rotated 3-D plots for the extracted components.

The contours in Figures 5a and 5b present a structural relationship described by the first and third retained components in the left hand side panel and the second and third components on the right. In each case the contour lines forming the function of the two retained kaolin components is shown on the horizontal and vertical axes. Each of the curves connects loadings in which the function is defined by the same particular value. Since, the gradient of the function is always perpendicular to the resulting contour lines the distance between the lines describes the gradient. Thus, the closer the lines are, the larger the gradient and so the higher the variation. Note in particular, the high variation associated with the extraction of the first component in both cases. In line with the rotations and contour plots in Figures $4 \mathrm{a}$ and $4 \mathrm{~b}$; and Figures $5 \mathrm{a}$ and 5 b, respectively, it is reasonable to adopt 3 main components as described in Table 5 . The insights into the nature of variation among the kaolins can be appreciated by both inspecting the loadings in Table 5 - partly discussed above - and via a 2-D plot of the eigenvectors.

It is important to note that Figure 1 which provides a basic understanding of the structures inherent in the data is heavily influenced by the particle cut-off points. For instance, creating less or more than four particle size classes would yield different patterns. This quite obvious issue has great relevance to all the analyses conducted above as it potentially describes multicollinearity as discussed above. The graphical data visualization tools such as the rotations in Figures $4 \mathrm{a}$ and $4 \mathrm{~b}$; and the contour plots in Figures $5 \mathrm{a}$ and $5 \mathrm{~b}$ served to validating the PCA results in Figure 3. A wide range of 3-rotations and contour plots involving up to 6 components were examined. Loadings of 0.7 or above yield three components, 0.6 or above would have produced 4 components while 0.5 or above would have produced 5. Loadings of 0.7 or above yield three components, 0.6 or above would have produced 4 components while 0.5 or above would have produced 5. Since loadings represent correlations between the original values and the factors (rows and columns), is reasonable to adopt values "significantly" above the arbitrary 0.5 and so 0.7 was chosen by examining the structural relationships between the all candidate 
Principal component analysis to evaluate spatial variation of major elements in kaolin deposit 49

components via rotations. The eigen values cut-off points are based on the same reasoning since they represent the contribution to the explanation of variation in the variables. Eigen values larger than 1 refer to components extracting at least as much variation as one original variable.

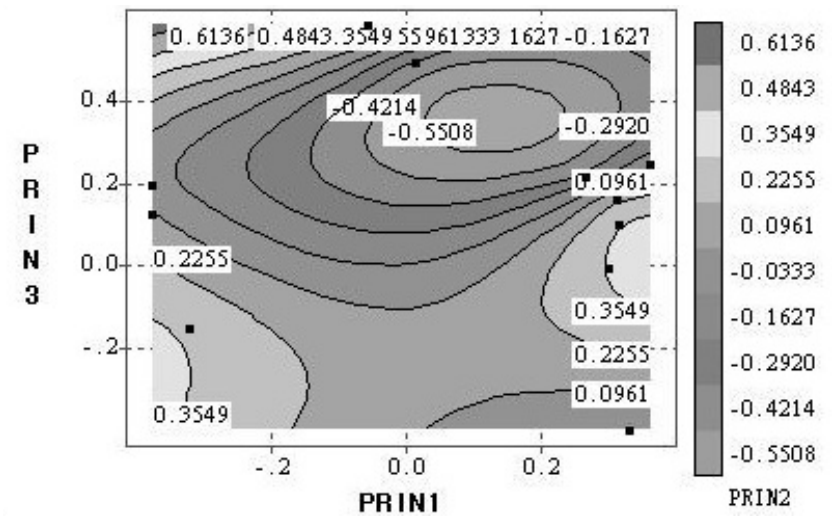

Figure 5a. 2-D contour plots involving each of the three principal components.

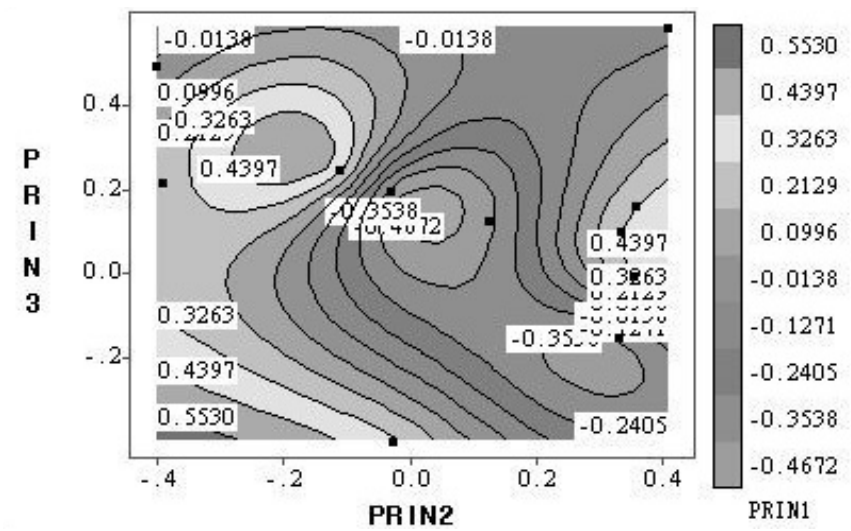

Figure 5b. 2-D contour plots involving each of the three principal components.

Table 5. Extracted eigen vectors for all the extracted components.

\begin{tabular}{|c|c|c|c|c|c|c|c|c|c|c|c|}
\hline PCOMP & $\mathrm{Na}_{2} \mathrm{O}$ & $\mathrm{MgO}$ & $\mathrm{Al}_{2} \mathrm{O}_{3}$ & $\mathrm{SiO}_{2}$ & $\mathrm{P}_{2} \mathrm{O}_{5}$ & $\mathrm{~K}_{2} \mathrm{O}$ & $\mathrm{CaO}$ & $\mathrm{TiO}_{2}$ & $\mathrm{MnO}$ & $\mathrm{Fe}_{2} \mathrm{O}_{3}$ & $\mathrm{LOI}$ \\
\hline PRIN1 & 0.318 & 0.365 & -0.378 & 0.333 & -0.056 & 0.269 & 0.314 & -0.323 & 0.014 & 0.300 & -0.380 \\
\hline PRIN2 & 0.337 & -0.110 & -0.029 & -0.024 & 0.413 & -0.391 & 0.362 & 0.335 & -0.402 & 0.358 & 0.128 \\
\hline PRIN3 & 0.108 & 0.254 & 0.207 & -0.395 & 0.598 & 0.223 & 0.168 & -0.144 & 0.502 & 0.002 & 0.133 \\
\hline PRIN4 & 0.164 & -0.228 & -0.067 & 0.206 & -0.171 & -0.457 & 0.060 & 0.202 & 0.748 & 0.120 & -0.132 \\
\hline PRIN5 & -0.180 & 0.226 & 0.284 & -0.462 & -0.514 & -0.022 & 0.198 & 0.052 & 0.011 & 0.562 & 0.004 \\
\hline PRIN6 & -0.801 & -0.072 & -0.238 & 0.228 & 0.328 & 0.028 & 0.084 & 0.054 & 0.080 & 0.344 & -0.033 \\
\hline PRIN7 & -0.059 & 0.011 & 0.090 & 0.030 & -0.073 & 0.419 & 0.399 & 0.690 & 0.035 & -0.298 & -0.286 \\
\hline PRIN8 & 0.037 & 0.052 & -0.484 & 0.006 & -0.231 & 0.175 & 0.217 & 0.101 & 0.119 & -0.057 & 0.777 \\
\hline PRIN9 & 0.184 & 0.235 & -0.915 & -0.031 & 0.098 & 0.215 & -0.698 & 0.460 & 0.051 & 0.339 & -0.013 \\
\hline PRIN10 & 0.035 & 0.202 & 0.619 & 0.650 & -0.009 & 0.112 & -0.007 & 0.029 & 0.027 & 0.144 & 0.342 \\
\hline PRIN11 & 0.180 & -0.764 & 0.091 & -0.025 & -0.009 & 0.500 & -0.010 & -0.134 & 0.036 & 0.324 & 0.023 \\
\hline
\end{tabular}

Bull. Chem. Soc. Ethiop. 2015, 29(1) 


\section{CONCLUSION}

This paper sought to identify distinctive oxides of elemental concentrations accounting for the highest variation in the kaolin samples as well as to validate the PCA results using graphical data visualization tools. The results show that the structural features of the detected components were in line with those generated by the original data attributes. It provided a basis for further investigations into how naturally arising structures in major elements concentrations of kaolins could be optimally utilized in understanding variations in chemical compositions of kaolins. The paper provided opportunities for developing robust analytical tools for comparing structural features in clays based on those of the original data attributes. The original data groupings obtained via PCA, rotations and contour plots provided valuable and consistent information relating to the kaolins and their oxides of elemental concentrations of the particle size fractions. The paper highlighted how the naturally arising structures in the major elements concentrations of kaolins could be utilised in understanding characteristics of kaolin chemical composition.

Key comparisons of the natural structures in the data may partly be a function of the discretisation of the particle sizes which created four distinct categories. In theory, the discretisation could yield extreme values of a single category or 28 distinct categories and so, while the decision to discretise may be taken on the basis of empirical scientific evidence and experience, we must always consider the possibility of a drift which may entail class adjustments. This is particularly important because identifying natural groupings in kaolins paves the way for carrying out comparative predictive modeling based on the class labels and a predictive model based on four classes may yield completely different information to that generated by a model based on, say, three classes. Thus, keeping track, synchronising and sharing information about the impact of discretisation of kaolin particle sizes across applications is one thing African clay scientists and data analysts must enforce. Further work could be directed at predictive modeling based on newly extracted components; and discretisation utilised in validating new predictive modeling applications.

It is expected that future analyses of kaolins will benefit from this study in a number of ways such as using the class attributes as class labels in predictive modeling. Most importantly, the paper recommends using the discretisation of the particle sizes as a tuning parameter in gauging kaolin variations across samples and validating new predictive modeling applications. Successful applications will depend on how clay and data scientists keep track, synchronise and share information relating to potentially dynamic data such as the impact of discretisation of kaolin particle sizes.

\section{ACKNOWLEDGEMENTS}

This work is part of the broader UNESCO/IUGS/IGCP 545 Project on Clays and Clay Minerals in Africa. Dr S. Vriend of Utrecht University in the Netherlands is acknowledged for assisting with the XRF analysis of the kaolin samples.

\section{REFERENCES}

1. Murray, H.H. Clay Minerals 1999, 34, 3949.

2. Ekosse, G. Appl. Clay Sci. 2000, 16, 301

3. Ekosse, G. Appl. Clay Sci. 2001, 20, 137.

4. Ekosse, G. X-Ray Powder Diffraction Patterns of Clays and Clay Minerals in Botswana, Associated Printers: Gaborone, Botswana; 2005.

5. Ekosse, G.; Mwitondi, K.S.M. Fresenius Environ. Bull. 2009, 18, 2234.

6. Van Der Merwe, G.; Laker, M.; Bühmann, C. Aust. J. Soil Res. 2002, 40, 115.

7. Bianchini, G.; Laviano, R.; Lovo, S.; Vaccaro, C. Appl. Clay Sci. 2002, 21, 165.

8. Rossel, R.; Walvoort, T.; McBratney, A.; Janik, L.; Skjemstad, J. Geoderma 2006, 131, 59. 
Principal component analysis to evaluate spatial variation of major elements in kaolin deposit 51

9. Mandal, U.K.; Warrington, D.N.; Bhardwaj, A.K.; Bar-Tal, A.; Kautsky, L.; Minz, D.; Levy, G.J. Geoderma 2008, 144, 189.

10. Skrbic, B.; Duris-Mladenovic, N. Chemosphere 2007, 68, 2144.

11. Aparicio, P.; Pérez-Bernal, J.L.; Gàlan, E.; Bello, M.A. Clay Minerals 2004, 39, 75.

12. Frost, R.L.; Carmody, O.; Kloprogge, J.T.; Mako, E.K.J.; Kokot, S. Appl. Spectr. 2006, 60, 1414.

13. Yuretich, R.F. Geol. Soc. London Spec. Publ. 1986, 25, 141.

14. Yap, C.T.; Younan, H. Appl. Spectros. 1992, 46, 1488.

15. Ekosse, G.; Mulaba-Bafubiandi, A.F. Kaolin occurrences in Botswana and possible uses as functional fillers, Proceedings of the $16^{\text {th }}$ Industrial Minerals International Congress, Montreal, Canada, 6-9 April 2003, 68-80, ISBN 190433307 9; 2003.

16. Gwosdz, W. Geological Survey of Botswana, Mineral Resources Report, 1985, 8, 157.

17. Carney, J.N.; Aldiss, D.T.; Lock, N.P. Geological Survey Department of Botswana Bulletin 1994, 37, 113.

18. Murray, H.H.; Keller, W.D. Kaolins, Kaolins and Kaolins in Murray, H.H.; Bundy, W.; Harvey, C. (Eds.) Kaolin Genesis and Utilization, Vol. 1, Clay Minerals Society: Boulder, CO, Special Publication; 1993; $p 1$.

19. Fitton, G. X-Ray Fluorescence Spectrometry in Modern Analytical Geochemistry: An Introduction to Quantitative Chemical Analysis Techniques for Earth, Environmental and Material Sciences, Gill, R. (Ed), Addison Wesley Longman: Harlow, England; 1997; pp 135-153.

20. Kaiser, H.F. Educ. Psychol. Measur. 1960, 20, 141.

21. Cattell, R.B. Multivar. Behavioral Res. 1966, 1, 629.

22. Cleveland, W.; Becker, R.; Weil, G. The Use of Brushing and Rotation for Data Analysis in Dynamic Graphics for Statistics, Cleveland, W.; McGill, M. (Eds.), Wadsworth and Brooks/Cole: Pacific Grove, California; 1988. 